\title{
Biofuel Cell Based Self-Powered Sensing Platform for L-Cysteine Detection
}

\author{
Chuantao Hou, ${ }^{\dagger}$ Shuqin Fan, ${ }^{\dagger} \dagger$ Qiaolin Lang, ${ }^{\dagger}$ and Aihua Liu ${ }^{*}, \dagger$ \\ ${ }^{\dagger}$ Laboratory for Biosensing, and Key Laboratory of Biofuels, Qingdao Institute of Bioenergy \& Bioprocess Technology, Chinese \\ Academy of Sciences, 189 Songling Road, Qingdao 266101, China \\ ${ }^{\ddagger}$ University of Chinese Academy of Sciences, 19A Yuquan Road, Beijing 100049, China
}

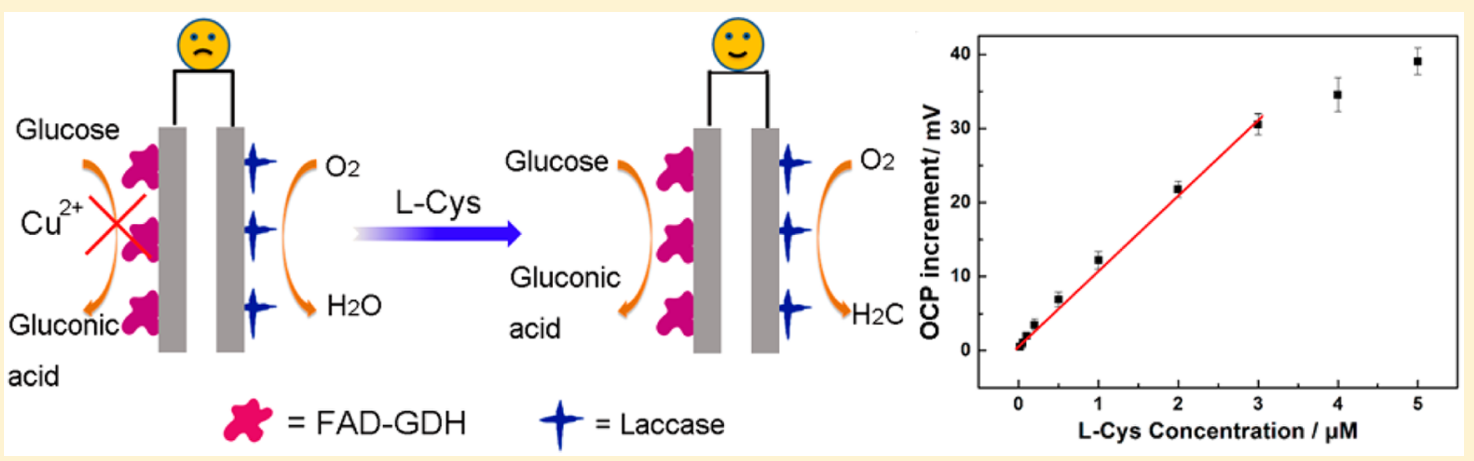

ABSTRACT: L-cysteine (L-Cys) detection is of great importance because of its crucial roles in physiological and clinical diagnoses. In this study, a glucose $/ \mathrm{O}_{2}$ biofuel cell (BFC) was assembled by using flavin adenine dinucleotide-dependent glucose dehydrogenase (FAD-GDH)-based bioanode and laccase-based biocathode. Interestingly, the open circuit potential (OCP) of the BFC could be inhibited by $\mathrm{Cu}^{2+}$ and subsequently activated by L-Cys, by which a BFC-based self-powered sensing platform for the detection of L-Cys was proposed. The FAD-GDH activity can be inhibited by $\mathrm{Cu}^{2+}$ and, in turn, subsequent reversible activation by L-Cys because of the binding preference of $\mathrm{L}-\mathrm{Cys}$ toward $\mathrm{Cu}^{2+}$ by forming the $\mathrm{Cu}-\mathrm{S}$ bond. The preferential interaction between L-Cys and $\mathrm{Cu}^{2+}$ facilitated $\mathrm{Cu}^{2+}$ to remove from the surface of the bioanode, and thus, the OCP of the system could be turned on. Under optimized conditions, the OCP of the BFC was systematically increased upon the addition of the LCys. The OCP increment ( $\triangle \mathrm{OCP}$ ) was linear with the concentration of L-Cys within $20 \mathrm{nM}$ to $3 \mu \mathrm{M}$. The proposed sensor exhibited lower detection limit of $10 \mathrm{nM}$ L-Cys $(\mathrm{S} / \mathrm{N}=3)$, which is significantly lower than those values for other methods reported so far. Other amino acids and glutathione did not affect $\mathrm{L}-\mathrm{Cys}$ detection. Therefore, this developed approach is sensitive, facile, cost-effective, and environmental-friendly, and could be very promising for the reliable clinically detecting of L-Cys. This work would trigger the interest of developing BFCs based self-powered sensors for practical applications.

$\mathrm{R}$ ecently, biofuel cells (BFCs) based self-powered sensors have attracted considerable attention because they can work without external power source and are well-suited for device miniaturization. ${ }^{1,2}$ The sensing mechanism is based on the fact that some parameters of the BFCs, such as the power density and open circuit potential (OCP), are significantly dependent on the concentration of the analytes. However, compared with a traditional electrochemical sensor, construction of such a sensing platform is challenging. To date, many kinds of self-powered platforms have been constructed for chemical and biological sensing, including the detection of glucose, ${ }^{3-5}$ cyanide, ${ }^{6} \mathrm{Hg}^{2+}$, and EDTA. ${ }^{8}$ Katz et al. first used $\mathrm{BFC}$ for glucose sensing, as the amount of power produced was a function of the amount of fuel glucose present. ${ }^{3}$ Dong et al. developed a BFC based self-powered sensor for cyanide detection, which used the inhibitive effect on microchip enzyme biofuel cell for sensing. ${ }^{6}$ In the presence of increasing concentrations of cyanide, the power response decreased due to the inhibition of the cathodic enzyme. ${ }^{6}$ Finally, this cyanide sensor showed a linear range of $0.3-500 \mu \mathrm{M}$ with a detection limit of $0.1 \mu \mathrm{M}$. Dong's group has also developed a $\mathrm{Hg}^{2+}$ sensor with a detection limit of $1 \mathrm{nM}$ based on the inhibitor effects of $\mathrm{Hg}^{2+}$ to alcohol dehydrogenase and bilirubin oxidase. ${ }^{7}$ Minteer explored the BFC-based self-powered sensor for nonredoxactive analytes detection. ${ }^{8}$ The self-powered EDTA sensor based on the inhibition of a mediated glucose oxidase bioanode by copper ions, and subsequent activation of the bioanode by EDTA. $^{8}$ Very recently, Deng et al. demonstrated a BFC based self-powered immunosensor for $\mathrm{N} \varepsilon$-(carboxymethyl)lysine detection. ${ }^{9}$

On the other hand, L-cysteine (L-Cys), a thiol-containing protein amino acid, is essential in maintaining regular function of the biological system. ${ }^{10,11}$ The abnormal level of L-Cys is associated with many diseases, such as liver damage, skin

Received: December 10, 2014

Accepted: February 25, 2015

Published: February 25, 2015 
lesions, slow growth, Alzheimer's disease, and cardiovascular disease. $^{12,13}$ Sensitive and selective detection of L-Cys is thus of interest for physiological and clinical diagnoses. In this respect, many methods for the detection of L-Cys have been developed and utilized, such as inductive coupled plasma atomic emission spectroscopy, ${ }^{14}$ atomic absorption spectrometry, ${ }^{15}$ time-resolved photoluminescence spectroscopy, ${ }^{16}$ capillary electrophoresis, ${ }^{17}$ and voltammetry. ${ }^{11}$ However, these methods experienced either expensive instrumentation, complicated operation procedures, or large sample volumes. BFC-based self-powered sensors have the inherent advantages of high sensitivity, relatively low cost, simple instrumentation, and selectivity by proper construction of the sensing platform, ${ }^{8}$ which should provide an alternative avenue to develop L-Cys sensor.

As an $\mathrm{O}_{2}$-insensitive enzyme, flavin adenine dinucleotidedependent glucose dehydrogenase (FAD-GDH) has been reported as a good candidate for the construction of onecompartment BFCs. ${ }^{18,19}$ Herein, we constructed a novel BFC with an OCP up to $780 \mathrm{mV}$ by using FAD-GDH-based bioanode and laccase-based biocathode, ${ }^{20}$ for efficient electron transport, menadione $\left(\mathrm{VK}_{3}\right)$ and 2,2'-azinobis(3-ethylbenzothiazoline-6-sulfonic acid) (ABTS) were adopted as mediators. $^{21}$ The $\mathrm{VK}_{3}$ and ABTS can dramatically increase the OCP value by decreasing the overpotential of the glucose oxidation at the bioanode and the oxygen reduction at the biocathode, respectively. The inhibition effect of $\mathrm{Cu}^{2+}$ toward $\mathrm{FAD}-\mathrm{GDH}$ and subsequent activation of L-Cys because of the binding preference of $\mathrm{L}-\mathrm{Cys}$ toward $\mathrm{Cu}^{2+}$ by forming a $\mathrm{Cu}-\mathrm{S}$ bond were verified. The preferential interaction between L-Cys and $\mathrm{Cu}^{2+}$ removes $\mathrm{Cu}^{2+}$ from the surface of the bioanode, and thus the OCP of the system could be turned on (Figure 1), which can

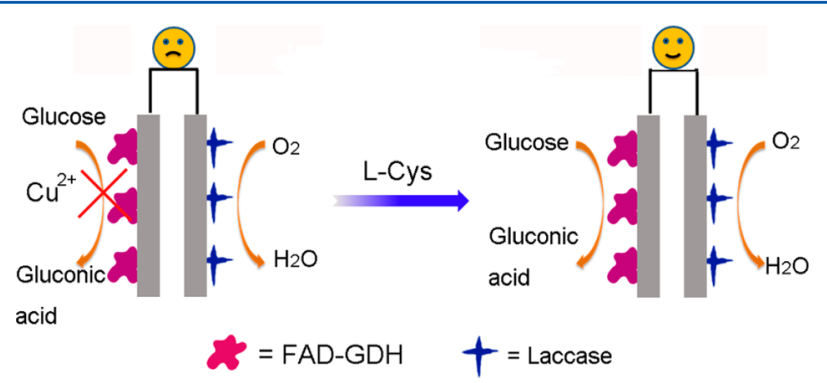

Figure 1. Schematic representation of the working principle of the BFC based self-powered sensing platform for the detection of $\mathrm{L}$-Cys.

be used as self-powered sensing platform for L-Cys detection. This method is facile, cost-effective, and environmentally friendly. Different from the reported work, ${ }^{8}$ our strategy for the first time constructed the linear relationship of OCP increment $(\triangle \mathrm{OCP})$ with $\mathrm{L}-\mathrm{Cys}$ concentration by inhibition and reactivation effect of the $\mathrm{BFC}$.

\section{EXPERIMENTAL SECTION}

Chemicals and Materials. FAD-GDH from Aspergillus sp. was purchased from Toyobo Co., Ltd. (Osaka, Japan). Laccase from Trametes versicolor was purchased from Sigma-Aldrich (St. Louis, MO USA). Glucose, $\mathrm{VK}_{3}, \mathrm{ABTS}$, and glutathione (GSH) were purchased from Aladdin Reagent Company (Shanghai, China). Amino acids such as L-Cys, L-glutamate (Glu),Lmethionone (Met), L-lysine, L-threonine, L-serine, L-argininie, Lvaline, L-aspartic acid, L-phenylalanine and L-leucine were purchased from Blue Quarter Science and Technology
Development Co., Ltd (Shanghai, China). All the chemicals were used without further purification. Multiwalled carbon nanotubes (MWCNTs) were kindly presented by Dr. Gebo Pan in Suzhou Institute of Nano-Tech and Nano-Biomics, Chinese Academy of Sciences.

Enzymatic Biofuel Cell Construction. Glassy carbon electrodes (GCE, $3 \mathrm{~mm}$ diameter) were cleaned before use by polishing with $0.05 \mu \mathrm{m}$ alumina and washed thoroughly. Bioanode was prepared as follows: $4 \mu \mathrm{L}$ of $2 \mathrm{mg} / \mathrm{mL}$ MWCNTs solution was dropped on the inverted GCE and dried at room temperature to prepare MWCNTs modified GCE; then $5 \mu \mathrm{L}$ of $0.29 \mathrm{M} \mathrm{VK}_{3}$ acetone solution and $10 \mu \mathrm{L}$ of FAD-GDH solution $(5 \mathrm{mg} / \mathrm{mL})$ were added, and the sample was dried at room temperature. Finally, $5 \mu \mathrm{L}$ of Nafion solution (0.05 wt \%) was syringed to the electrode surface. Before use, the modified electrode was washed repeatedly with Milli-Q water to remove any loosely combined modifiers.

For preparation of the laccase based biocathode, a $10 \mu \mathrm{L}$ of laccase $(5 \mathrm{mg} / \mathrm{mL})$ aqueous solution was coated on the MWCNTs modified GCE and then cross-linked with $2 \mu \mathrm{L}$ of glutaraldehyde ( $2 \mathrm{wt} \%)$, finally dried in the fridge $\left(4{ }^{\circ} \mathrm{C}\right)$ overnight. The resultant electrode was rinsed thoroughly with distilled water before use.

The glucose $/ \mathrm{O}_{2}$ BFC which employed $\mathrm{FAD}-\mathrm{GDH} / \mathrm{VK}_{3} /$ MWCNTs/GCE as the bioanode and the laccase/MWCNTs/ GCE as biocathode, was assembled in one compartment containing $30 \mathrm{mM}$ glucose buffered with $0.1 \mathrm{M}$ acetate solution ( $5 \mathrm{~mL}, \mathrm{pH} 5.5$ ). To improve the bioelectrocatalysis efficiency of the laccase-based biocathode toward $\mathrm{O}_{2}$ reduction, ABTS was used as a redox mediator.

Electrochemical Measurements. Electrochemical experiments were carried out with a $\mathrm{CHI} 660 \mathrm{D}$ potentiostat $(\mathrm{CH}$ Instruments, Chenhua, Shanghai, China). The half-cell measurement was carried out in a conventional three-electrode system using the as-prepared bioelectrode as working electrode, Pt wire electrode as auxiliary electrode, and a saturated calomel electrode (SCE) as reference electrode. All potentials in this study were recorded versus this reference.

Self-Powered Detection of L-Cys. The linear range of inhibition effect of $\mathrm{Cu}^{2+}$ toward the glucose $/ \mathrm{O}_{2} \mathrm{BFC}$ was first studied. A specific concentration of $\mathrm{Cu}^{2+}$ was added to the cell and incubated for $20 \mathrm{~min}$ at room temperature before the electrochemical measurements. The final concentration of $\mathrm{Cu}^{2+}$ ranged from 0 to $20 \mu \mathrm{M}$. For comparison, different anions with the same concentration to $\mathrm{Cu}^{2+}$ were added to the cell and incubated for $20 \mathrm{~min}$ at room temperature.

For the detection of $\mathrm{L}-\mathrm{Cys}, \mathrm{Cu}^{2+}$ with a final concentration of $4 \mu \mathrm{M}$ was added to the $\mathrm{BFC}$, and then different concentrations of L-Cys were added. The final concentration of L-Cys ranged from 0 to $5 \mu \mathrm{M}$. After $20 \mathrm{~min}$, the OCP of the BFC was recorded.

\section{RESULTS AND DISCUSSION}

Characterization of the Glucose/ $\mathrm{O}_{2}$ BFC. Figure $2 \mathrm{~A}$ shows the cyclic voltammogram (CVs) of the FAD-GDH/ $\mathrm{VK}_{3} / \mathrm{MWCNTs} / \mathrm{GCE}$ bioanode with and without the addition of $30 \mathrm{mM}$ glucose. In the absence of glucose, a pair of redox peak at ca. $-280 \mathrm{mV}$ was observed, resulting from the reversible transition between menadione and menadiol. ${ }^{22}$ After the addition of $30 \mathrm{mM}$ glucose, a remarkable increase in the anodic current was found, indicating the efficient oxidation of glucose. For the $\mathrm{FAD}-\mathrm{GDH}$-based bioanode, $\mathrm{VK}_{3}$ has been demonstrated to be an efficient mediator for the oxidation of 

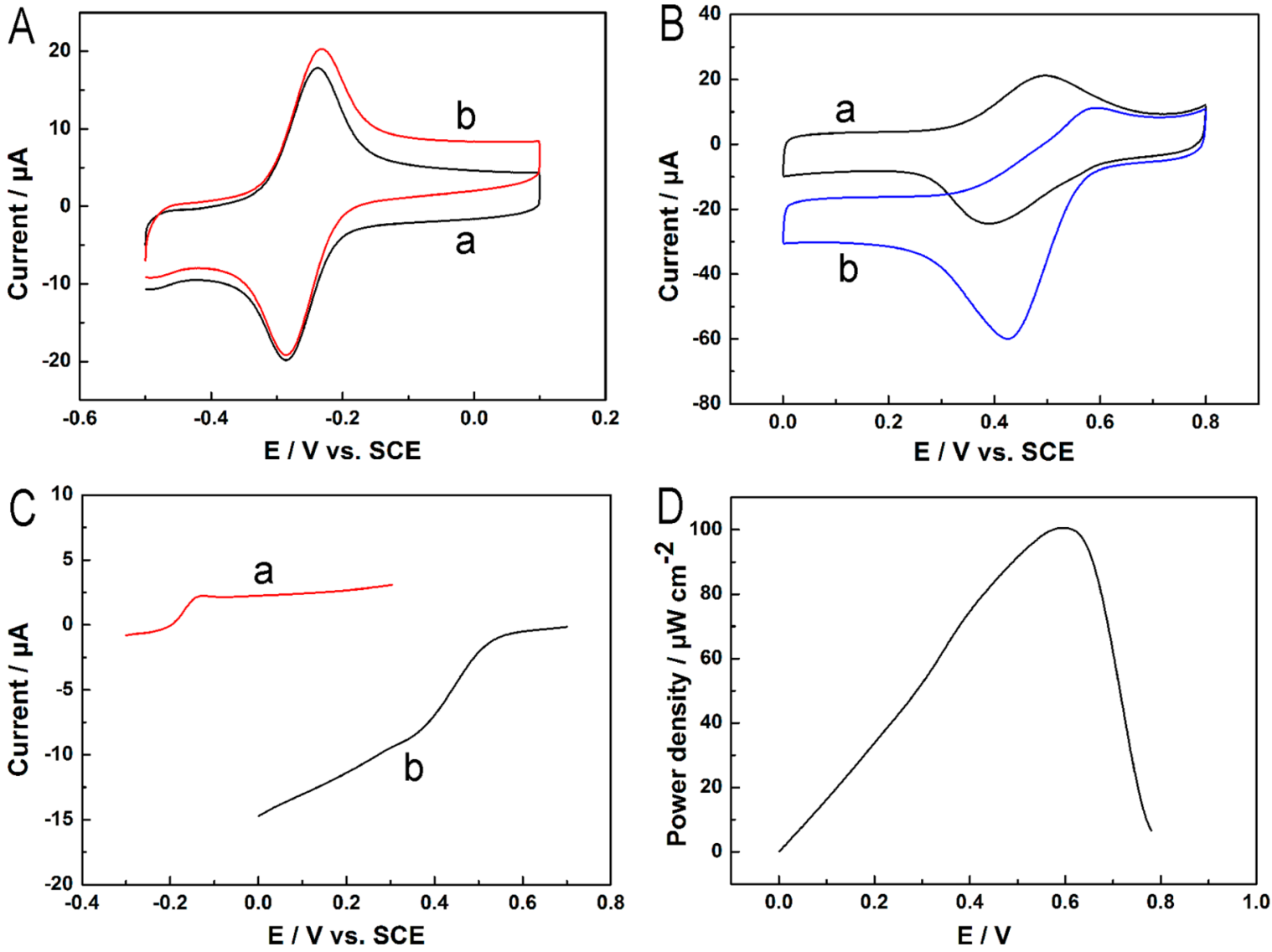

Figure 2. Characterization of the glucose $/ \mathrm{O}_{2}$ BFC: (A) CVs obtained at the FAD-GDH/VK $/ \mathrm{MWCNTs}_{3} / \mathrm{GCE}$ bioanode in the (a) absence and (b) presence of $30 \mathrm{mM}$ glucose. Scan rate: $20 \mathrm{mVs}^{-1}$. (B) CVs obtained at the laccase/MWCNTs/GCE containing ABTS under the (a) sat. $\mathrm{N}_{2}$ and (b) sat. $\mathrm{O}_{2}$ condition. Scan rate: $20 \mathrm{mVs}^{-1}$. (C) Polarization curves of the (a) bioanode and (b) biocathode. (D) Dependence of the power density on the cell voltage in $0.1 \mathrm{M}$ acetate buffer $(\mathrm{pH} 5.5)$ under saturated $\mathrm{O}_{2}$ atmosphere containing $1 \mathrm{mM}$ ABTS and $30 \mathrm{mM}$ glucose.

$\mathrm{FADH}_{2}$ in the redox cycling during glucose oxidation. ${ }^{23}$ In fact, no obvious anodic current increase was observed in the absence of $\mathrm{VK}_{3}$ as a mediator because the enzyme was not able to transfer electrons to the electrode directly. ${ }^{24}$

Analogously, the remarkable cathodic current increase in Figure 2B demonstrated the high efficiency of oxygen reduction at the laccase-based biocathode. As we know, for a given fuel cell assembly, the OCP is determined by the difference between the onset potential for catalysis at the bioanode and biocathode. ${ }^{25}$ The polarization curves of the bioelectrodes at the presence of glucose and $\mathrm{O}_{2}$ were recorded in Figure 2C. The onset potential of the glucose oxidation was $-180 \mathrm{mV}$, while that of the $\mathrm{O}_{2}$ reduction was about $590 \mathrm{mV}$, suggesting a much lower overpotential at the bioanode and the biocathode. This phenomenon indicates the efficient electrocatalytic activity of the $\mathrm{VK}_{3}$ and the ABTS mediator systems at the bioelectrodes. Subsequently, a glucose $/ \mathrm{O}_{2}$ biofuel cell was assembled by associating the bioanode and biocathode in one compartment. For the proposed BFC, the output potential was $780 \mathrm{mV}$, and the maximum power density was $98 \mu \mathrm{W} \mathrm{cm}{ }^{-2}$ at $580 \mathrm{mV}$, in $30 \mathrm{mM}$ glucose solution under $\mathrm{O}_{2}$-saturated atmosphere (Figure 1D). The OCP approximated the difference between the onset potential for catalysis at the bioanode and biocathode.

The OCP of the bioelectrodes and the BFC was also measured. As shown in Figure 3, the OCP of the bioanode and the biocathode was -188 and $597 \mathrm{mV}$, respectively. The OCP of the BFC was $780 \mathrm{mV}$ (Figure 3A, curve c), which agreed well with the results of the polarization curves (Figure 2C,D). Because stability should be of importance for the performance of a designed sensor, the OCP stability was also measured to determine the possibility of the OCP of our BFC as a sensing signal. Here, the BFC maintained $97 \%$ of its OCP during $9 \mathrm{~h}$ of continuous operation, indicating a comparatively stable power output process (Figure 3B).

Inhibition Effect of $\mathrm{Cu}^{2+}$ and Activation Effect of L-Cys. To understand the inhibition effect of $\mathrm{Cu}^{2+}$ toward the OCP signal of the BFC, we recorded the OCP of the BFC upon the addition of different concentrations of $\mathrm{Cu}^{2+}$. As shown in Figure 4A, the OCP at the bioanode shifted from $-188 \mathrm{mV}$ (curve a) to $-107 \mathrm{mV}$ (curve b) and $135 \mathrm{mV}$ (curve c) after the addition of $10 \mu \mathrm{M}$ and $1 \mathrm{mM} \mathrm{Cu}^{2+}$, respectively. This result obviously indicated the efficient inhibition of $\mathrm{Cu}^{2+}$ toward the FAD-GDH enzyme. On the contrary, the OCP shift at the biocathode could be almost ignored, suggesting noninhibition of $\mathrm{Cu}^{2+}$ toward laccase and the ABTS mediator. This phenomenon can be explained by the inhibition effect resulting from the interaction between the $\mathrm{Cu}^{2+}$ and the $\mathrm{FAD}$ active sites. $^{26}$

It was reported that $\mathrm{L}-\mathrm{Cys}$ could react with $\mathrm{Cu}^{2+}$ by the formation of $\mathrm{Cu}-\mathrm{S}$ bond; this preferential interaction, competitive with the FAD-GDH, may activate the enzyme activity again. ${ }^{27-29}$ Therefore, the inhibition and activation effect can be explored to probe L-Cys based on the possible mechanism that L-Cys and FAD-GDH compete for $\mathrm{Cu}^{2+}$. To verify this hypothesis, we added both $\mathrm{Cu}^{2+}$ and $\mathrm{L}-\mathrm{Cys}$ to the 

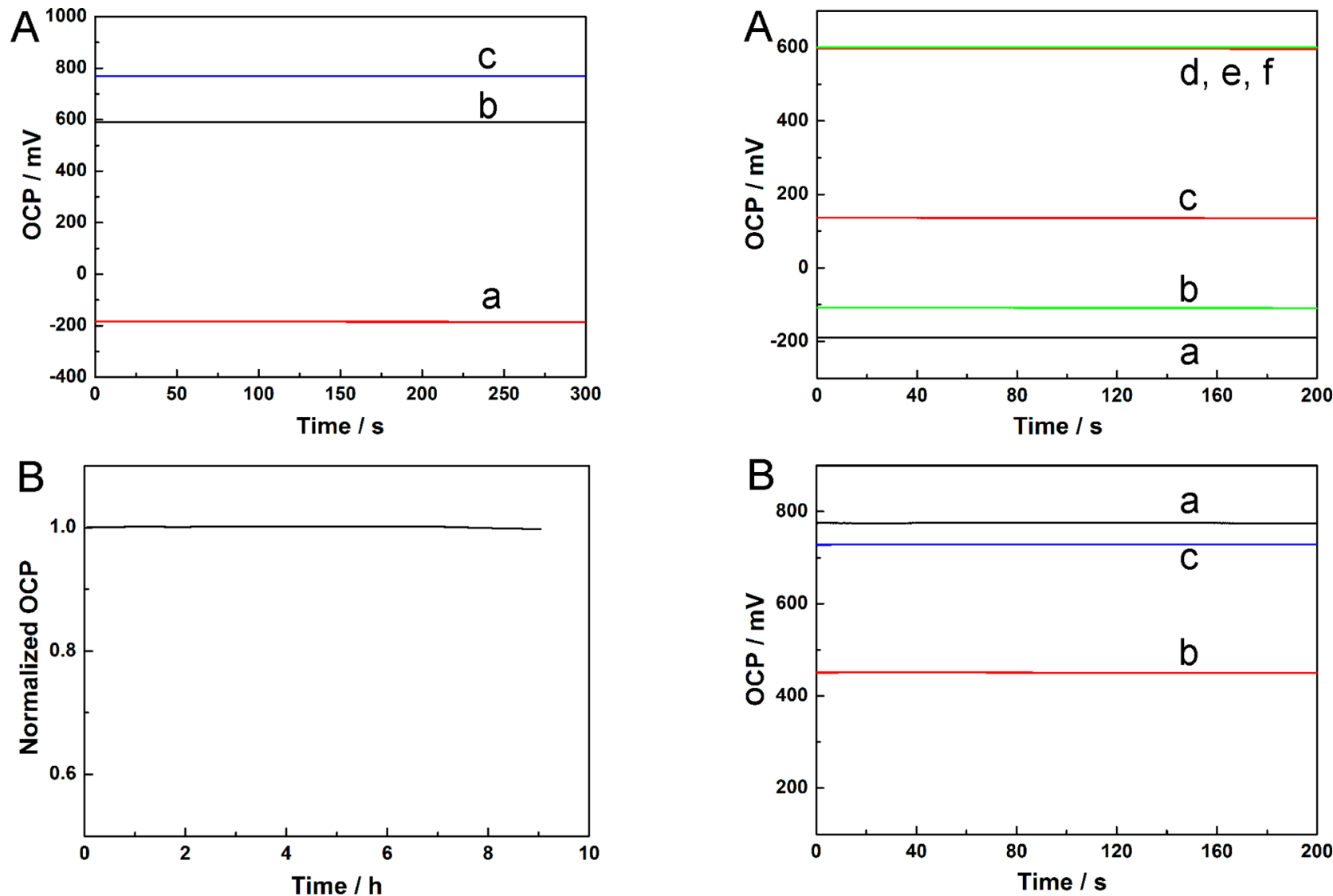

Figure 3. (A) The OCP of the (a) bioanode, (b) biocathode, and (c) the BFC. (B) Stability of the OCP of the glucose $/ \mathrm{O}_{2} \mathrm{BFC}$ during continuous operation.

BFC in sequence, and the OCP changes are shown in Figure 4B. After the addition of $1 \mathrm{mM} \mathrm{Cu}^{2+}$, the OCP dropped from 780 to $451 \mathrm{mV}$. When $1 \mathrm{mM}$ L-Cys was continuously added, it recovered to $728 \mathrm{mV}, 94 \%$ of its original value. Hence, selfpowered sensing platform based on the inhibition and activation effect can be achieved.

The Inhibition Effect of $\mathrm{Cu}^{2+}$ on OCP. The linear range of the $\triangle \mathrm{OCP}_{1}$ (the difference between OCP of the BFC in the absence of $\mathrm{Cu}^{2+}$ and OCP of the BFC in the presence of $\mathrm{Cu}^{2+}$ ) as a function of $\mathrm{Cu}^{2+}$ concentration in the $\mathrm{BFC}$ was studied. As shown in Figure 5, upon the addition of $\mathrm{Cu}^{2+}$, significant decrease in OCP can be observed, and the OCP decreased gradually with the increasing $\mathrm{Cu}^{2+}$ concentration due to the inhibition effect of the $\mathrm{Cu}^{2+}$ toward FAD-GDH. The calibration curves in Figure 5B shows a linear relationship $\left(R^{2}=0.997\right)$ of $\Delta \mathrm{OCP}_{1}$ versus the concentration of $\mathrm{Cu}^{2+}$ within $0.1-4 \mu \mathrm{M}$.

To evaluate whether other possible cations inhibit OCP of the $\mathrm{BFC}$, we measured the OCP changes in the presence of various ions including $\mathrm{Fe}^{3+}, \mathrm{Fe}^{2+}, \mathrm{Co}^{2+}, \mathrm{Ni}^{2+}, \mathrm{Mg}^{2+}, \mathrm{Ca}^{2+}, \mathrm{Zn}^{2+}$, $\mathrm{Na}^{+}, \mathrm{K}^{+}$, and $\mathrm{NH}_{4}^{+}$under the same conditions. The ratio of $\Delta \mathrm{OCP}_{\mathrm{M}}$ (the $\triangle \mathrm{OCP}$ induced by other metal ions) to $\Delta \mathrm{OCP}_{\mathrm{Cu}}$ (the $\Delta$ OCP induced by $\mathrm{Cu}^{2+}$ ) as a function of metal ions type is shown in Figure 6. $\mathrm{Zn}^{2+}, \mathrm{Na}^{+}, \mathrm{K}^{+}$, and $\mathrm{NH}_{4}^{+}$caused negligible OCP change (the ratio is less than $6 \%$ ), while other metal ions $\left(\mathrm{Fe}^{3+}, \mathrm{Fe}^{2+}, \mathrm{Co}^{2+}, \mathrm{Ni}^{2+}, \mathrm{Mg}^{2+}\right.$, and $\left.\mathrm{Ca}^{2+}\right)$ induced a $20 \% \mathrm{OCP}$ decrease. Only $\mathrm{Cu}^{2+}$ can lead to the significant decrease of the OCP value. So $\mathrm{Cu}^{2+}$ is a favorable ion capable of efficient inhibition of enzyme activity.

Figure 4. (A) OCP curves obtained at the bioelectrodes of the glucose $/ \mathrm{O}_{2} \mathrm{BFC}$ in the ( $\mathrm{a}$ and $\left.\mathrm{d}\right)$ absence and ( $\mathrm{b}$ and $\mathrm{e}$ ) presence of $10 \mu \mathrm{M}$ and (c and f) $1 \mathrm{mM} \mathrm{Cu}^{2+}$. The three curves at (a) -188 , (b) -107 , and (c) $135 \mathrm{mV}$ were obtained at the bioanode; and $(\mathrm{d}-\mathrm{f})$ the three overlapped curves at ca. $600 \mathrm{mV}$ obtained at the biocathode indicated noninhibition effect of the $\mathrm{Cu}^{2+}$ toward laccase and the ABTS mediator. (B) OCP curves of the (a) BFC and those of the BFC in the presence of (b) $1 \mathrm{mM} \mathrm{Cu}^{2+}$ and (c) $1 \mathrm{mM}$ L-Cys. OCP curves were recorded in $0.1 \mathrm{M}$ acetate buffer $(\mathrm{pH} 5.5)$ under saturated $\mathrm{O}_{2}$ atmosphere containing $1 \mathrm{mM} \mathrm{ABTS}$ and $30 \mathrm{mM}$ glucose.

Detection of L-Cys. For the detection of L-Cys, a final concentration of $4 \mu \mathrm{M} \mathrm{Cu}^{2+}$ was added to the BFC (denoted as $\mathrm{Cu}^{2+}-\mathrm{BFC}$ ), and then $\mathrm{L}-\mathrm{Cys}$ with various concentrations were added. The OCP of the BFC was recorded until a stable response was observed. The data is shown in Figure 7A. Upon the addition of $\mathrm{L}-\mathrm{Cys}$, the competitive interaction between $\mathrm{Cu}^{2+}$ and $\mathrm{L}-\mathrm{Cys}$ would lessen the inhibition effect of the $\mathrm{Cu}^{2+}$ toward FAD-GDH. The different OCP responses upon the addition of $\mathrm{L}$-Cys make it possible to be used for $\mathrm{L}$-Cys detection. Figure $7 \mathrm{~B}$ shows the calibration curve, in which the increase in $\triangle \mathrm{OCP}_{2}$ value (the difference between OCP of the $\mathrm{Cu}^{2+}-\mathrm{BFC}$ in the absence of $\mathrm{L}-\mathrm{Cys}$ and OCP of the $\mathrm{Cu}^{2+}-\mathrm{BFC}$ in the presence of $\mathrm{L}$-Cys) increased linearly with the increasing L-Cys concentration ranging from $20 \mathrm{nM}$ to $3 \mu \mathrm{M}\left(R^{2}=0.993\right)$. The linear range of our method is comparable to those reported for other electrochemical sensors. ${ }^{11,30}$ The lower detection limit was estimated to be $10 \mathrm{nM}$ L-Cys $(\mathrm{S} / \mathrm{N}=3)$, which is significantly lower than those values reported at the $\mathrm{NiO} /$ polypyrrole-Au modified GCE (350 nM), ${ }^{31}$ the $\mathrm{Pt}$ nanoparticles/poly $(o$ aminophenol) modified GCE $(80 \mathrm{nM}),{ }^{32}$ and $\mathrm{CdS}$ quantum dots based photoelectrochemical sensor $(100 \mathrm{nM}){ }^{33}$ Therefore, our method is sensitive and facile for $\mathrm{L}$-Cys detection. The reproducibility of the BFC based self-powered sensor toward L- 

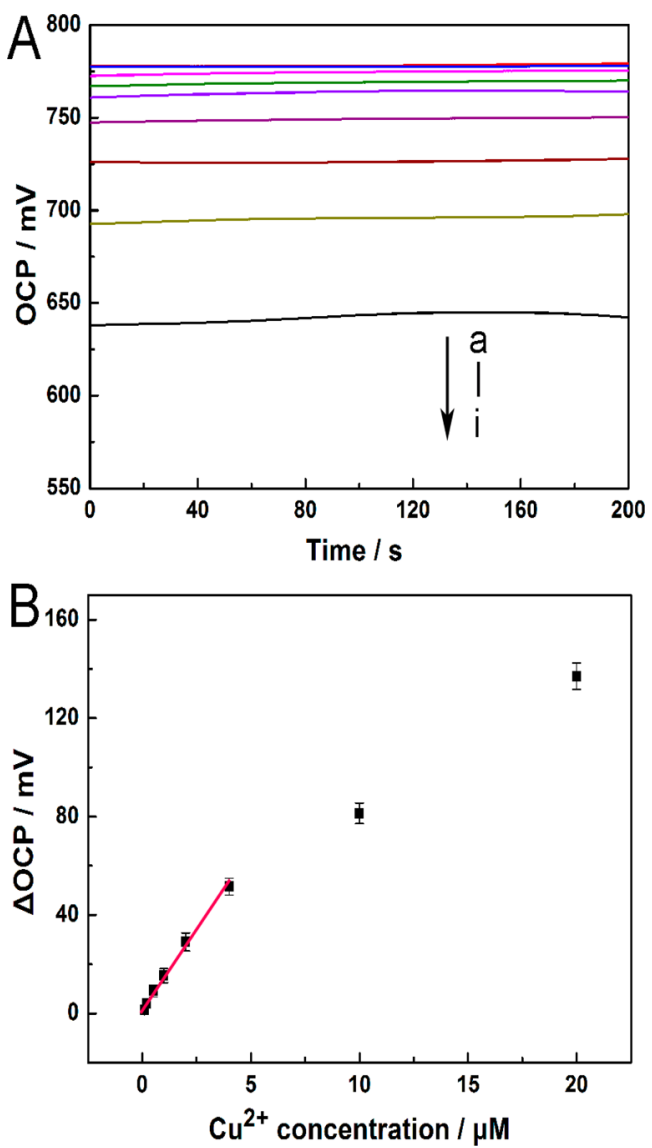

Figure 5. (A) OCP of the BFC in $0.1 \mathrm{M}$ acetate buffer ( $\mathrm{pH} 5.5$ ) containing $0,0.1,0.2,0.5,1,2,4,10$, and $20 \mu \mathrm{M}$ (from a to i) $\mathrm{Cu}^{2+}$. (B) Typical calibration graph for $\mathrm{Cu}^{2+}$.

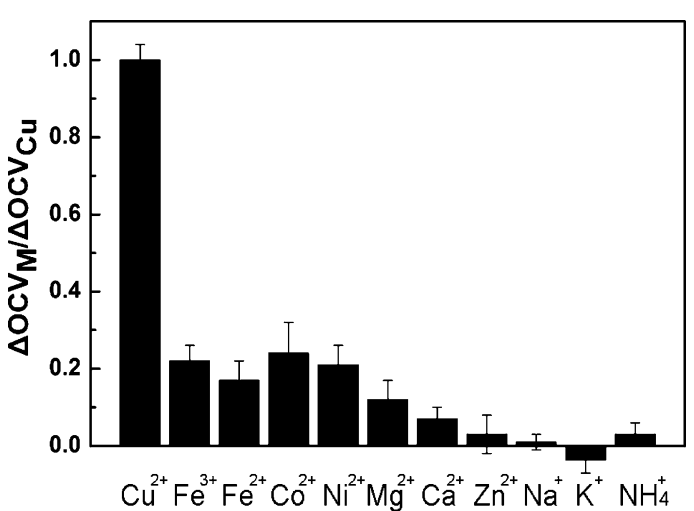

Figure 6. OCP changes of the BFC resulted from various metal ions.

Cys detection was also investigated by performing six separate experiments. The relative standard deviation was calculated to be $6.0 \%$, indicating the good reproducibility of the sensor.

To further evaluate the selectivity of the proposed method, we used other amino acids and GSH instead of L-Cys separately in the system with a final concentration of $4 \mu \mathrm{M}$. The ratio of $\Delta \mathrm{OCP}_{\text {In }}$ (the $\triangle \mathrm{OCP}$ induced by $\mathrm{Cu}^{2+}$ in the presence of other species) to $\Delta \mathrm{OCP}_{\mathrm{Cu}}$ (the $\triangle \mathrm{OCP}$ induced by $\mathrm{Cu}^{2+}$ only) as a function of species type is shown in Figure 8. In the presence of other amino acids without containing $-\mathrm{SH}$ or disulfide bond in their structures, the $\Delta \mathrm{OCP}_{\text {In }}$ values were actually the same as that in the presence of $\mathrm{Cu}^{2+}$ (Figure 8; for clarity, only Gly and Glu were shown), suggesting their noninterference. Met
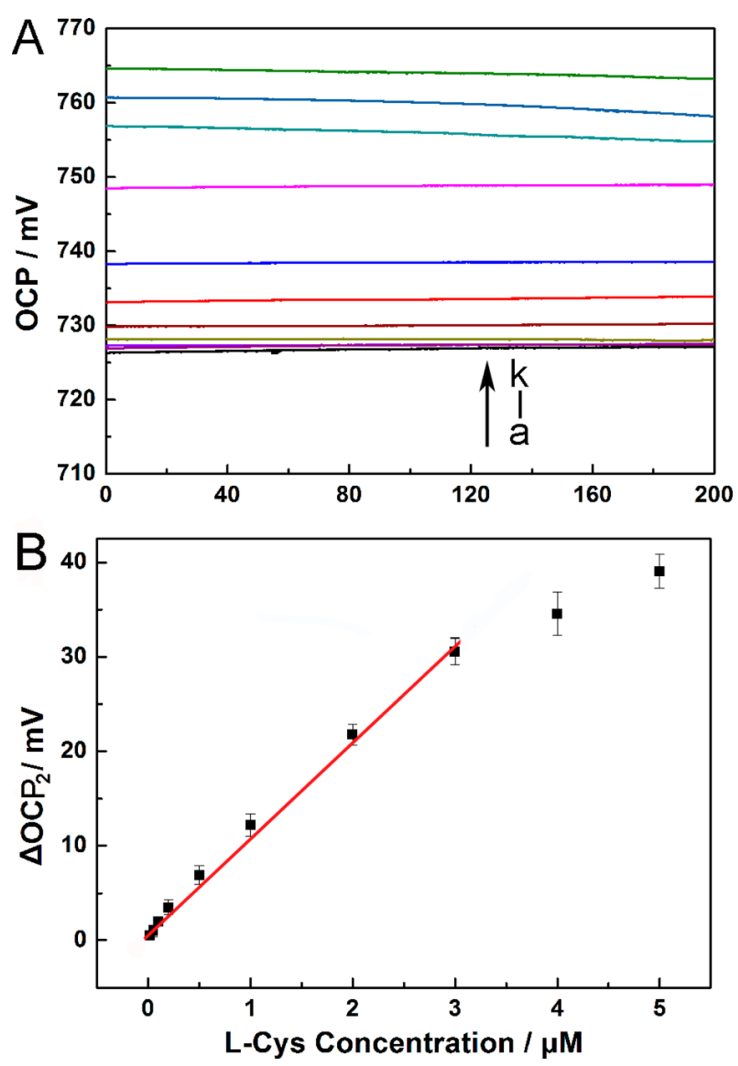

Figure 7. (A) OCP of the BFC in $0.1 \mathrm{M}$ acetate buffer ( $\mathrm{pH} 5.5$ ) containing $4 \mu \mathrm{M} \mathrm{Cu}^{2+}$ and L-Cys with varying concentrations of 0 , $0.02,0.05,0.1,0.2,0.5,1,2,3,4$, and $5 \mu \mathrm{M}$ (from a to k). (B) Typical calibration curve for L-Cys.

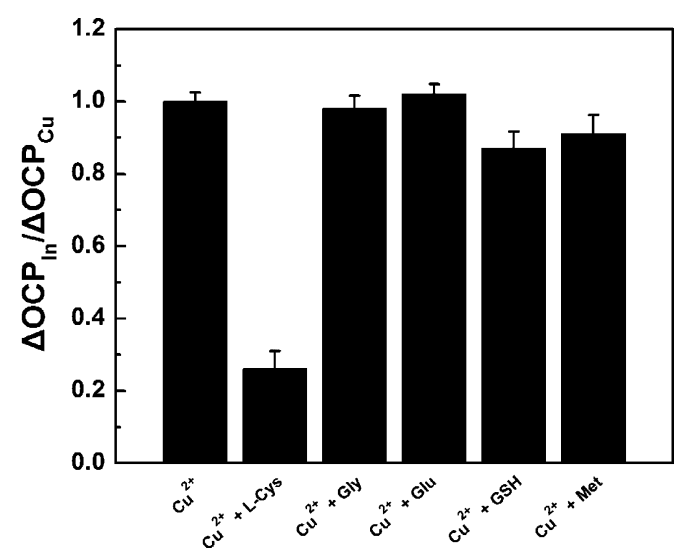

Figure 8. Normalized $\triangle \mathrm{OCP}$ of the self-powered sensor in response to $\mathrm{L}-\mathrm{Cys}$ and other possible interferents.

exhibited about $8 \%$ decrease in the $\Delta \mathrm{OCP}_{\text {In }}$ value, suggesting the slight interference from Met, which is probably originating from the disulfide bond in its structure, which may be partially dissociated to form thiol group in the presence of $\mathrm{Cu}^{2+}$, followed by forming $\mathrm{Cu}-\mathrm{S}$ bond. However, Met level only accounts for one-fifth to one-half of other free amino acid concentrations in plasma and urine. ${ }^{34}$ Therefore, Met will not affect the L-Cys measurement in real plasma and urine samples. GSH has exhibited about $10 \%$ decrease in the $\Delta \mathrm{OCP}_{\text {In }}$ value, nevertheless, no significant interference on the L-Cys detection. Taken together, this self-powered L-Cys sensor shows good 
selectivity against other interferences, which could promise the possibility of its application in real samples.

\section{CONCLUSIONS}

In summary, by rationally utilizing the competitive interaction between $\mathrm{Cu}^{2+}$ and L-Cys completing for FAD-GDH, we have successfully demonstrated a BFC-based self-powered platform for the sensing of $\mathrm{L}_{\text {-Cys. }} \mathrm{Cu}^{2+}$ can decrease the OCP of the $\mathrm{BFC}$ through the inhibition effect toward FAD-GDH. Upon the addition of $\mathrm{L}$-Cys into the BFC, the OCP can be recovered. The OCP increment was linear with the concentration of L-Cys from $20 \mathrm{nM}$ to $3 \mu \mathrm{M}$. This method is simple, facile, cheap, and environmental-friendly and could thus be very promising for the reliably sensing of L-Cys in real sample. In the future, more work will focus on developing other self-powered sensors for the detection of various biomolecules.

\section{AUTHOR INFORMATION}

\section{Corresponding Author}

*E-mail: liuah@qibebt.ac.cn.

\section{Notes}

The authors declare no competing financial interest.

\section{ACKNOWLEDGMENTS}

This work was financially supported by National Natural Science Foundation of China (Nos. 91227116, 21275152, and 21475144) and Key Laboratory of Biofuels, Qingdao Institute of Bioenergy and Bioprocess Technology, Chinese Academy of Sciences (CASKLB201505). C.T.H. acknowledges the financial support from the Postdoctoral Science Foundation of China (No.2014M560586).

\section{REFERENCES}

(1) Zhou, M.; Wang, J. Electroanalysis 2012, 24, 197-209.

(2) Arechederra, R. L.; Minteer, S. D. Anal. Bioanal. Chem. 2011, 400, $1605-1611$.

(3) Katz, E.; Buckmann, A. F.; Willner, I. J. Am. Chem. Soc. 2001, 123, 10752-10753.

(4) Liu, Z.; Cho, B.; Ouyang, T.; Feldman, B. Anal. Chem. 2012, 84, 3403-3409.

(5) Kakehi, N.; Yamazaki, T.; Tsugawa, W.; Sode, K. Biosens. Bioelectron. 2007, 22, 2250-2255.

(6) Deng, L.; Chen, C.; Zhou, M.; Guo, S.; Wang, E.; Dong, S. Anal. Chem. 2010, 82, 4283-4287.

(7) Wen, D.; Deng, L.; Guo, S.; Dong, S. Anal. Chem. 2011, 83, 3968-3972.

(8) Meredith, M. T.; Minteer, S. D. Anal. Chem. 2011, 83, 54365441.

(9) Cheng, J.; Han, Y.; Deng, L.; Guo, S. Anal. Chem. 2014, 86, 11782-11788.

(10) Silva Fde, A.; da Silva, M. G.; Lima, P. R.; Meneghetti, M. R.; Kubota, L. T.; Goulart, M. O. Biosens. Bioelectron. 2013, 50, 202-209.

(11) Lai, Y. T.; Ganguly, A.; Chen, L. C.; Chen, K. H. Biosens. Bioelectron. 2010, 26, 1688-1691.

(12) Chen, H.; Li, X.; Wu, Y.; Gao, W.; Bai, R. Dalton Trans. 2012, 41, 13292-13297.

(13) Wang, W.; Rusin, O.; Xu, X.; Kim, K. K.; Escobedo, J. O.; Fakayode, S. O.; Fletcher, K. A.; Lowry, M.; Schowalter, C. M.; Lawrence, C. M.; Fronczek, F. R.; Warner, I. M.; Strongin, R. M. J. Am. Chem. Soc. 2005, 127, 15949-15958.

(14) G. H, Tao; Sturgeon, R. E. Spectrochim. Acta, Part B 1999, 54, 481-489.

(15) Ghaedi, M.; Ahmadi, F.; Shokrollahi, A. J. Hazard. Mater. 2007, 142, 272-278.
(16) Huang, K.; Bulik, I. W.; Marti, A. A. Chem. Commun. 2012, 48, $11760-11762$.

(17) Li, X. A.; Zhou, D. M.; Xu, J. J.; Chen, H. Y. Talanta 2007, 71, $1130-1135$.

(18) Katz, E.; MacVittie, K. Energy Environ. Sci. 2013, 6, 2791-2803.

(19) Yehezkeli, O.; Tel-Vered, R.; Raichlin, S.; Willner, I. ACS Nano 2011, 5, 2385-2391.

(20) Hou, C.; Yang, D.; Liang, B.; Liu, A. Anal. Chem. 2014, 86, $6057-6063$

(21) Lang, Q.; Yin, L.; Shi, J.; Li, L.; Xia, L.; Liu, A. Biosens. Bioelectron. 2014, 51, 158-163.

(22) Sakai, H.; Nakagawa, T.; Tokita, Y.; Hatazawa, T.; Ikeda, T.; Tsujimura, S.; Kano, K. Energy Environ. Sci. 2009, 2, 133-138.

(23) Fapyane, D.; Lee, S. J.; Kang, S. H.; Lim, D. H.; Cho, K. K.; Nam, T. H.; Ahn, J. P.; Ahn, J. H.; Kim, S. W.; Chang, I. S. Phys. Chem. Chem. Phys. 2013, 15, 9508-9512.

(24) Tsujimura, S.; Kojima, S.; Kano, K.; Ikeda, T.; Sato, M.; Sanada, H.; Omura, H. Biosci. Biotechnol. Biochem. 2006, 70, 654-659.

(25) Cracknell, J. A.; Vincent, K. A.; Armstrong, F. A. Chem. Rev. 2008, 108, 2439-2461.

(26) Ghica, M. E.; Brett, C. M. A. Microchim. Acta 2008, 163, 185193.

(27) Deng, J.; Yu, P.; Yang, L.; Mao, L. Anal. Chem. 2013, 85, 25162522.

(28) Li, Q.; Guo, Y.; Shao, S. Sens. Actuators, B: Chem. 2012, 171$172,872-877$.

(29) Li, F.; Wang, J.; Lai, Y.; Wu, C.; Sun, S.; He, Y.; Ma, H. Biosens. Bioelectron. 2013, 39, 82-87.

(30) Hallaj, R.; Salimi, A.; Akhtari, K.; Soltanian, S.; Mamkhezri, H. Sens. Actuators B: Chem. 2009, 135, 632-641.

(31) Jia, D.; Ren, Q.; Sheng, L.; Li, F.; Xie, G.; Miao, Y. Sens. Actuators, B: Chem. 2011, 160, 168-173.

(32) Liu, L. P.; Yin, Z. J.; Yang, Z. S. Bioelectrochemistry 2010, 79, 84-89.

(33) Long, Y. T.; Kong, C.; Li, D. W.; Li, Y.; Chowdhury, S.; Tian, H. Small 2011, 7, 1624-1628.

(34) Kume, S.; Araki, S.; Ono, N.; Shinhara, A.; Muramatsu, T.; Araki, H.; Isshiki, K.; Nakamura, K.; Miyano, H.; Koya, D.; Haneda, M.; Ugi, S.; Kawai, H.; Kashiwagi, A.; Uzu, T.; Maegawa, H. PloS one 2014, 9, e101219. 